\title{
THIẾU HỤT NGUỒN NƯớC NGỌT Ở ĐỒNG BẰNG SÔNG CỦU LONG: HIỆN TRẠNG VÀ DỬ BÁO ĐẾN NĂM 2030 VÀ 2050 DƯớI TÁC ĐộNG CỦA BIẾN ĐỔI KHÍ HẬU
}

\author{
Trần Xuân Hải ${ }^{1}$, Bùi Nguyễn Lâm Hà ${ }^{2}$ Phạm Anh Tài ${ }^{1}$, Đỗ Ngọc Tuấn ${ }^{1}$, \\ Vũ Văn Nghị ${ }^{3}$, Đặng Thanh Lâm ${ }^{4}$
}

Tóm tắt: Hiện trạng và dụ báo khan hiếm nguồn nước ngọt cho 120 khu thủy lợi thuộc ĐBSCL theo các kịch bản phát triển kinh tế xã hội và biến đổi khi hậu - nước biển dâng được đánh giá dựa trên tính toán cân bằng nước thông qua các bước xác định nhu cầu nước và mô phỏng xâm nhập mặn bằng mô hình MIKE11. Kết quả cho thấy, thiếu hụt nước vào mùa khô ở ĐBSCL hiện trạng vào khoảng 4,0 tỉ $\mathrm{m}^{3}$ hàng năm, dụ báo lên tới 4,8 tỉ $\mathrm{m}^{3}$ vào năm 2030 và 5,0 tỉ $\mathrm{m}^{3}$ vào năm 2050. Nguyên nhân là do nhu cầu sủ dụng nước ngọt ở ĐBSCL là rất lớn với giá trị hiện trạng vào khoảng 22,8 tỉ $m^{3}$, tăng lên 28,6 tỉ $m^{3}$ vào năm 2030 và 29,2 tỉ $m^{3}$ vào năm 2050, cùng với đó là xâm nhập mặn ngày càng tiến sâu vào nọi đồng.

Từ khóa: Đồng bằng sông Cửu Long, cân bằng nước, thiếu hụt nguồn nước, xâm nhập mặn.

Ban Biên tập nhận bài: 12/08/2019 Ngày phản biện xong: 20/09/2019 Ngày đăng bài: 25/10/2019

\section{Mở đầu}

Đồng bằng sông Cửu Long (ĐBSCL) là một bộ phận của châu thổ sông Mê Công thuộc Việt Nam có diện tích khoảng 3,9 triệu ha. ĐBSCL có vị trí rất quan trọng trong phát triển kinh tế-xã hội và là chìa khoá chính trong chiến lược an ninh lương thực Quốc gia. Với tiềm năng nông nghiệp và thuỷ sản to lớn, trong những năm qua, ĐBSCL luôn đóng góp khoảng 53\% tổng sản lượng lương thực, $65 \%$ sản lượng thuỷ sản nuôi trồng và $70 \%$ trái cây của cả nước. Tuy nhiên, ĐBSCL cũng luôn đối mặt với vấn đề khan hiếm nguồn nước ngọt.

Đánh giá và dự báo thiếu hụt nhu cầu sử dụng nước là vấn đề tiên quyết cần được xác định trong quy hoạch xây dựng các công trình thủy lợi nhằm đảm bảo an ninh nguồn nước, phục vụ phát triển bền vững kinh tế xã hội. Tuy nhiên đến

${ }^{1}$ Viện Khoa học và Đổi mới công nghệ, TP.HCM ${ }^{2}$ Truờng ĐH Đà Lạt, TP. Đà Lạt, Lâm Đồng

${ }^{3}$ Truờng ĐH Khoa học Tụ nhiên, ĐH Quốc gia TP.HCM

${ }^{4}$ Viện Quy hoạch Thủy lợi miền Nam, TP.HCM Email:txhai@bwe.com.vn nay những nghiên cứu vấn đề này chưa tổng thể. Các nghiên cứu trong nước chủ yếu: (1) Tập trung phân tích và đánh giá cân bằng nước riêng lẻ cho từng lưu vực sông nhánh thuộc lưu vực sông Cửu Long như nhóm nghiên cứu Đặng Đình Khá [4], Nguyễn Xuân Phùng [9]; (2) Tập trung phân tích và đánh giá riêng lẻ từng vấn đề liên quan đến nước tại vùng ĐBSCL như ứng dụng mô hình MIKE 11 mô phỏng và tính toán xâm nhập mặn cho khu vực Nam Bộ của Đoàn Quang Trí [5], sự thay đồi thủy văn, thủy lực ở Đồng Tháp Mười dước tác động của hệ thống đê bao của Cấn Thu Văn và cộng sự [1], phân tích ảnh hưởng của các hồ đập thượng lưu đến thay đổi thủy văn dòng chảy mùa khô về châu thổ Mê Công của Tô Quang Toản và cộng sự [11], mô phỏng xâm nhập mặn đồng bằng sông Cửu Long dưới tác động mực nước biển dâng và sự suy giảm lưu lượng từ thượng nguồn của nhóm tác giả Trần Quốc Đạt [13]. Nhiều nghiên cứu nước ngoài cũng đề cập đến vấn đề nước ở ĐBSCL, tuy nhiên cũng như các công bố trong nước, chúng chỉ tập trung vào xâm nhập mặn và nhu cầu sử dụng nước cho nông nghiệp, điển hình 


\section{BÀI BÁO KHOA HỌC}

như nghiên cứu của Chu Thai Hoanh [2], Van [10], FAO [6], Thomas Sagris [12], Dang Kieu Nhan [3], Mekong River Commission [8], JICA [7].

Thông qua các bước tính toán nhu cầu sử dụng nước cho hoạt động dân sinh kinh tế và mô phỏng xâm nhập mặn bằng mô hình MIKE 11 , bài báo này sẽ trình bày kết quả đánh giá sự thiếu hụt nguồn nước ngọt cho 120 khu thủy lợi vùng ĐBSCL giai đoạn hiện trạng và dự báo đến 2030 và 2050 dưới tác động của biến đổi khí hậu - nước biển dâng (BĐKH-NBD).

\section{Phương pháp nghiên cứu và tài liệu thu}

\section{thập}

2.1. Phạm vi và không gian đánh giá sụ thiếu hụt nhu cầu sử dụng nước

Khai thác sử dụng nước ở ĐBSCL chủ yếu ở dạng nước mặt, do đó bài toán thiếu hụt nguồn nước cần được đánh giá cho từng khu thủy lợi. Theo Phân viện Khảo sát Quy hoạch Thủy lợi Nam bộ năm 1998, không gian ĐBSCL được phân định thành 120 khu thủy lợi (Hình 1).

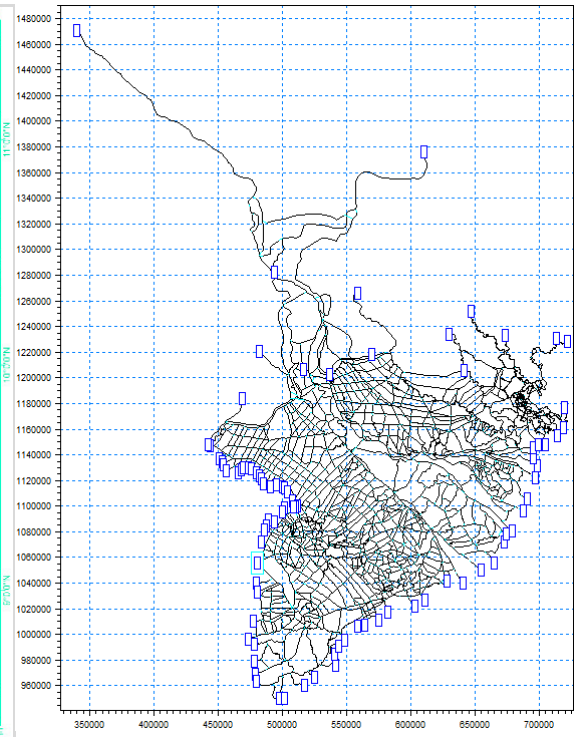

Hình 1. Phân khu thủy lợi và so đồ mô phỏng thủy lực, xâm nhập mặn ĐBSCL

\subsection{Phuơng pháp và tài liệu tính toán}

\subsubsection{Nhu cầu sủ dung nước ngọt}

Nhu cầu sử dụng nước $(\mathrm{NCN})$ được xác định theo từng mục đích sử dụng và theo từng khu thủy lợi với bước thời gian tính toán hàng tháng trong năm trên cơ sở định mức sử dụng nước đối sinh hoạt, công nghiệp, du lịch, chăn nuôi, thủy sản, y tế, dự phòng; và mô hình CROPWAT 8.0 đối với trồng trọt. Các tài liệu để tính toán cho từng giai đoạn bao gồm:

- Giai đoạn hiện trạng: Số liệu niên giám thống kê năm 2015-2016; dữ liệu khí tượng (nhiệt độ, độ ẩm, số giờ nắng, tốc độ gió, mưa) giai đoạn 1981-2016 từ tất cả các trạm cơ bản ở ĐBSCL.

- Giai đoạn dự báo 2030 và 2050: Các tài liệu quy hoạch sử dụng đất, quy hoạch công nghiệp, nông nghiệp, nuôi trồng thủy hải sản, y tế, tài liệu dự báo dân số Việt Nam 2014-2049, dữ liệu mưa và nhiệt độ, và kịch bản $\mathrm{BĐKH} \mathrm{RCP} 4.5$ của Bộ Tài nguyên và Môi trường (BTNMT) năm 2016.

2.2.2. Mô phỏng xâm nhập mặn và tính toán cân bằng nước

\section{a) Thiết lập mô hình}

Mô hình MIKE 11 được sử dụng trong nghiên cứu này với các mô đun như mưa-dòng chảy NAM, thủy động lực học (HD) và tảikhuếch tán $(\mathrm{AD})$.

Sơ đồ được thiết lập trong phạm vi từ Kratie trên dòng chính sông Mê Công, vùng lòng hồ TonleSap (Campuchia) đến các cửa sông thuộc ĐBSCL của Việt Nam và hạ lưu lưu vực hệ thống sông Đồng Nai:

- Sơ đồ thủy lực bao gồm 988 nhánh sông với 7189 mặt cắt ngang và 19251 nút được thiết lập 
chi tiết đến các kênh cấp 2 và một số kênh cấp 3 có độ rộng lớn, 147 cống kiểm soát xâm nhập mặn chính ở các sông kênh vùng ven biển ở ĐBSCL và 120 điểm khai thác nguồn nước.

- Trong sơ đồ thủy lực bao gồm: (1) 8 biên lưu lượng thượng lưu, trong đó biên lưu lượng tại Kratie có ảnh hưởng lớn tới kết quả của mô hình; các biên khác có trị số lưu lượng nhỏ hoặc tác động không đáng kể; (2) 32 biên mực nước ven biển Đông và 39 biên mực nước ven biển Tây;

- Ngoài lưu lượng thượng lưu, lưu lượng bên nhập vào 33 nhánh sông từ 30 tiểu lưu vực được mô phỏng bằng mô hình $\mathrm{NAM}$, trong đó 14 tiểu lưu vực thuộc địa phận Campuchia và 16 tiểu lưu vực phía Việt Nam.

Các dữ liệu đầu vào mô hình cụ thể như sau:

- Dữ liệu khí tượng thực đo từ 1981-2016, trong đó dữ liệu mưa ngày tại 22 trạm phía Campuchia, 30 trạm phía Việt Nam,và bộ thông số mô hình NAM được lấy theo kinh nghiệm để xác định lưu lượng nhập bên (vì không có tài liệu kiểm định mô hình mưa dòng chảy, trong nghiên cứu này bộ thông số mô hình NAM tham khảo từ lưu hồ Dầu Tiếng);

- Dữ liệu biên thực đo (2000-2016): Biên lưu lượng ngày tại Kratie, Trị An, Phước Hòa, Dầu Tiếng; và biên mực nước giờ tại trạm Vũng Tàu, Vàm Kênh, Bình Đại, Bến Trại, Mỹ Thanh, Gành Hào (ven biển Đông), Sông Đốc và Rạch Giá (ven biển Tây);

- Nhánh sông, mặt cắt ngang sông và các công trình kiểm soát xâm nhập mặn được kế thừa từ nguồn dữ liệu của Viện Quy hoạch Thủy lợi Miền Nam, số liệu địa hình các kênh rạch trong nội đồng được cập nhật đến 2016 từ các báo cáo của Chi cục Thủy lợi các tỉnh ĐBSCL;

- Dũ liệu mực nước và lưu lượng giai đoạn 1981-2016 được thu thập từ các trạm thủy văn vùng ĐBSCL dùng làm tài liệu hiệu chỉnh, kiểm định mô hình;

- Số liệu độ mặn các tháng mùa kiệt của năm 2011 và 2016 được thu thập từ các trạm đo mặn trong vùng ĐBSCL dùng để hiệu chỉnh, kiểm định mô hình.

\section{b) Kịch bản tính toán}

Bốn kịch bản mô phỏng được xây dựng, bao gồm:

- Kịch bản 1: Kịch bản nền năm 2015 với mực nước triều trung bình nhiều năm;

- Kịch bản 2: Kịch bản hiện trạng khan hiếm nguồn nước do tác động của con người (khai thác nguồn nước) với điều kiện mặn xâm nhập sâu vào trong nội đồng của năm 2016;

- Kịch bản 3: Kịch bản dự báo theo quy hoạch phát triển kinh tế xã hội (nhu cầu khai thác nguồn nước) và dưới tác động của $\mathrm{BĐKH-NBD}$ năm 2030 (RCP4.5 của BTNMT, 2016);

- Kịch bản 4: Kịch bản dự báo theo quy hoạch phát triển kinh tế xã hội (nhu cầu khai thác nguồn nước) và dưới tác động của $\mathrm{BĐKH-NBD}$ năm 2050 (RCP4.5 của BTNMT, 2016).

\section{Kết quả và thảo luận}

\subsection{Nhu cầu sử dụng nước}

$\mathrm{NCN}$ hàng tháng ở ĐBSCL được xác định theo từng mục đích sử dụng ở 120 khu thủy lợi thuộc ĐBSCL trong giai đoạn hiện trạng với dữ liệu niêm giám thống kê năm 2015 và dự báo đến 2030 và 2050 trên cơ sở dữ liệu quy hoạch phát triển kinh tế xã hội và có tính đến $\mathrm{BĐKH}$ (mưa và nhiệt độ) theo kịch bản RCP 4.5. Kết quả được thống kê trong Bảng 1.

Kết quả cho thấy tổng NCN hiện trạng ở ĐBSCL là rất lớn, trung bình khoảng 22,8 tỉ $\mathrm{m}^{3} /$ năm, trong đó NCN cho nông nghiệp chiếm tỷ trọng lên đến $91,3 \%$ và tập trung $75 \%$ vào mùa khô từ tháng XII - IV. Tháng I và II có nhu cầu sử dụng nước lớn nhất (chiếm 34\% tổng NCN cả năm), lý do bởi đây là thời kỳ mùa khô và rơi vào chính vụ Đông Xuân ở ĐBSCL.

Dự báo tổng NCN năm 2030 là 28,6 tỉ m ${ }^{3}$ và năm 2050 là 29,2 tỉ m³ ; so với hiện trạng, tổng $\mathrm{NCN}$ tăng lên $20 \%$ vào năm 2030 và $22 \%$ vào năm 2050. Mức tăng này chủ yếu vào mùa khô, cụ thể là $41,3 \%$ vào năm 2030 và $42,7 \%$ vào năm 2050 . NCN cho nông nghiệp vẫn chiếm tỷ trọng $91 \%$ trong tổng NCN của cả vùng. Sự gia tăng nhu cầu sử dụng nước, đặc biệt lĩnh vực nông nghiệp, đồng nghĩa với việc chúng ta phải có biện pháp công trình thủy lợi điều phối nguồn 


\section{BÀI BÁO KHOA HỌC}

nước triển khai kịp thời, bởi như đã biết đợt hạn và xâm nhập mặn do triều cường năm 2016 gây thiệt hại rất lớn cho nông dân ĐBSCL và hiện tượng này sẽ hiện diện thường xuyên trong tương lai theo dự đoán theo kịch bản BĐKH.

Bảng 1. Nhu cầu nước của tùng ngành $\left(10^{6} \mathrm{~m}^{3}\right)$ ở ĐBSCL

\begin{tabular}{lccccccccc}
\hline $\begin{array}{c}\text { Kịch } \\
\text { bản }\end{array}$ & $\begin{array}{c}\text { Sinh } \\
\text { hoạt }\end{array}$ & $\begin{array}{c}\text { Trồng } \\
\text { trọt }\end{array}$ & $\begin{array}{c}\text { Chăn } \\
\text { nuôi }\end{array}$ & $\begin{array}{c}\text { Thủy } \\
\text { sản }\end{array}$ & $\begin{array}{c}\text { Công } \\
\text { nghiệp }\end{array}$ & $\begin{array}{c}\text { D. lịch } \\
\text { D. vụ }\end{array}$ & Y tế & $\begin{array}{c}\text { Dự } \\
\text { phòng }\end{array}$ & Tổng \\
\hline HT & 605,1 & 14.811 & 96,2 & 5.943 & 147,2 & 121,0 & 7,4 & 1.087 & 22.818 \\
2030 & 641,8 & 12.113 & 96,5 & 13.854 & 414,5 & 128,4 & 9,1 & 1.363 & 28.610 \\
2050 & 668,5 & 12.502 & 104,1 & 13854 & 508,8 & 133,7 & 11,8 & 1389 & 29.172 \\
\hline
\end{tabular}

\subsection{Diễn biến xâm nhập mặn}

3.2.1 Kết quả hiệu chỉnh và kiểm định mô hinh

Mô hình được đánh giá theo hai bước: (1) Mô phỏng dòng chảy và (2) xâm nhập mặn. Kết quả

Bảng 2. Kết quả hiệu chỉnh và kiểm định mô đun thuỷ lục trong thời kì mùa kiệt tù̀ tháng 1 đến tháng 6 năm 2011 và 2016

\begin{tabular}{llcccc}
\hline \multirow{2}{*}{ TT } & \multirow{2}{*}{ Trạm thủy văn } & \multicolumn{2}{c}{ Mực nước } & \multicolumn{2}{c}{ Lưu lượng } \\
\cline { 3 - 6 } & & Hiệu chỉnh & Kiểm định & Hiệu chỉnh & Kiểm định \\
\hline 1 & Tân châu & 0,78 & 0,98 & 0,94 & 0,98 \\
2 & Châu Đốc & 0,88 & 0,96 & 0,87 & 0,96 \\
3 & Long Xuyên & 0,71 & - & - & - \\
4 & Vàm Nao & 0,94 & 0,95 & 0,92 & 0,95 \\
5 & Cao Lãnh & - & - & 0,94 & - \\
6 & Cần Thơ & 0,93 & 0,97 & 0,97 & 0,98 \\
7 & Phụng Hiệp & 0,96 & - & 0,92 & - \\
8 & Đại Ngãi & 0,97 & - & 0,97 & - \\
9 & Mỹ Thuận & 0,97 & 0,95 & 0,96 & 0,97 \\
10 & Trà Vinh & - & - & 0,97 & - \\
11 & Chợ Lách & - & - & 0,85 & - \\
12 & Mỹ Tho & 0,98 & - & 0,91 & - \\
13 & Bến Lức & - & - & 0,88 & - \\
14 & Tân An & 0,90 & - & 0,86 & - \\
\hline
\end{tabular}

Ghi chú: “- “Không có dũ liệu so sánh.

Đối với mô phỏng lan truyền mặn, việc hiệu chỉnh phức tạp hơn so với mô hình thủy động lực vì dữ liệu thực đo mặn không liên tục và đôi khi không đảm bảo tính đặc trưng do hạn chế trong công tác lấy mẫu (ví dụ, mẫu nước thường quan trắc sát bờ trong khi mặn chịu ảnh hưởng của nhiều yếu tố như thời tiết, các công trình khai thác và xả thải vào nguồn nước, ,...). Hơn nữa, hệ thống sông, kênh rạch vùng ĐBSCL khá phức tạp nên việc xác định chính xác giá trị của hiệu chỉnh và kiểm định quá trình mô phỏng dòng chảy được thể hiện trong Bảng 2 với chỉ tiêu đánh giá của mô hình là $\mathrm{R}^{2}$ (Nash) tại các trạm thủy văn vùng ĐBSCL năm 2011 và 2016. 

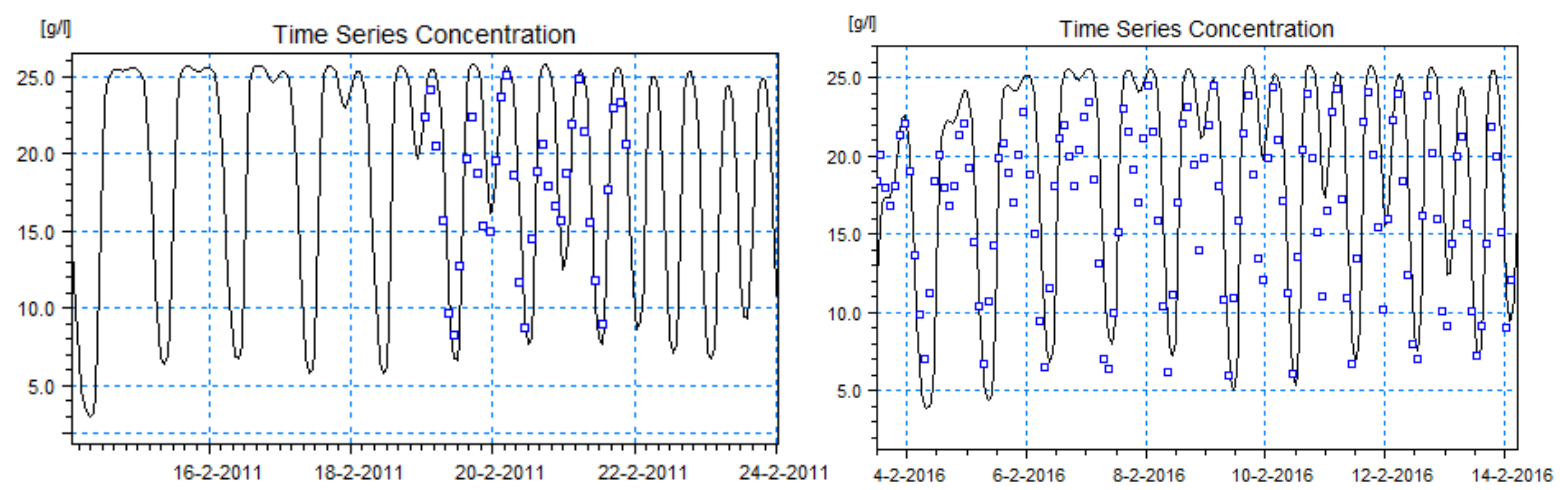

Hình 2. Nồng độ mặn mô phỏng và thực đo thời kì hiệu chỉnh và kiểm định tại trạm Vàm Kênh

Mặc dù còn một số hạn chế, đặc biệt là trong thủ tục đánh giá xâm nhập mặn như đã phân tích trên, kết quả hiệu chỉnh và kiểm định (Bảng 2 và Hình 2) nhìn chung vẫn thể hiện tính phù hợp giữa giá trị mô phỏng và thực đo theo không gian, thời gian và đảm bảo độ tin cậy để tính toán dự báo dòng chảy và xâm nhập mặn trong mùa kiệt theo các phương án, kịch bản khác nhau.

\subsubsection{Kết quả mô phỏng xâm nhập mặn}

Kịch bản 1, ranh giới mặn ở ngưỡng 0,25 g/1 (ngưỡng mặn tiêu chuẩn cho nước sinh hoạt) tiến sâu nhất vào khoảng $143 \mathrm{~km}$ trên sông Vàm Cỏ Đông và Vàm Cỏ Tây, 90 km trên sông Tiền, vượt hợp lưu sông Hàm Luông và lân cận khu vực thị trấn Chợ Lách, 70 km trên sông Hậu, 55 km trên sông Cái Lớn và $25 \mathrm{~km}$ trên sông Cái Bé. Đối với ngưỡng 2,5 g/1 (ngưỡng mặn tiêu chuẩn cho nước dùng để tưới), ranh mặn trên sông Hàm Luông cách cửa biển khoảng 52 km, sông Cổ Chiên là 41 km và sông Hậu là 59 km.

Bảng 3. Ranh giới xâm nhập mặn lớn nhất theo các kịch bản

\begin{tabular}{ccccccccc}
\hline \multirow{2}{*}{$\begin{array}{c}\text { Kịch } \\
\text { bản }\end{array}$} & \multirow{2}{*}{$\begin{array}{c}\text { Ngưỡng } \\
\text { mặn }\end{array}$} & $\begin{array}{c}\text { Vàm Cỏ } \\
\text { Đông }\end{array}$ & $\begin{array}{c}\text { Vàm Cỏ } \\
\text { Tây }\end{array}$ & $\begin{array}{c}\text { Hàm } \\
\text { Luông }\end{array}$ & $\begin{array}{c}\text { Cổ } \\
\text { Chiên }\end{array}$ & Hậu & Cái Lớn & Cái Bé \\
\hline 2015 & 0,25 & 143 & 143 & 90 & 48 & 70 & 55 & 25 \\
& 2,5 & 112 & 110 & 52 & 41 & 59 & 34 & 18 \\
& 4 & 100 & 100 & 47 & 38 & 51 & 30 & 17 \\
& 6 & 85 & 87 & 44 & 36 & 44 & 27 & 15 \\
2016 & 0,25 & 135 & 152 & 82 & 56 & 76 & 58 & 36 \\
& 2,5 & 110 & 120 & 66 & 46 & 67 & 51 & 29 \\
& 4 & 103 & 111 & 62 & 43 & 64 & 48 & 28 \\
& 6 & 88 & 97 & 58 & 41 & 58 & 44 & 26 \\
& 0,25 & 160 & 162 & 92 & 49 & 72 & 55 & 23 \\
& 2,5 & 123 & 124 & 76 & 42 & 63 & 32 & 18 \\
& 4 & 111 & 111 & 55 & 40 & 55 & 27 & 17 \\
& 6 & 96 & 97 & 51 & 37 & 52 & 24 & 16 \\
& 0,25 & 161 & 164 & 96 & 50 & 71 & 56 & 34 \\
& 2,5 & 121 & 120 & 78 & 42 & 63 & 35 & 21 \\
& 4 & 114 & 113 & 56 & 40 & 56 & 31 & 20 \\
& 6 & 100 & 98 & 53 & 38 & 53 & 27 & 18 \\
\hline
\end{tabular}



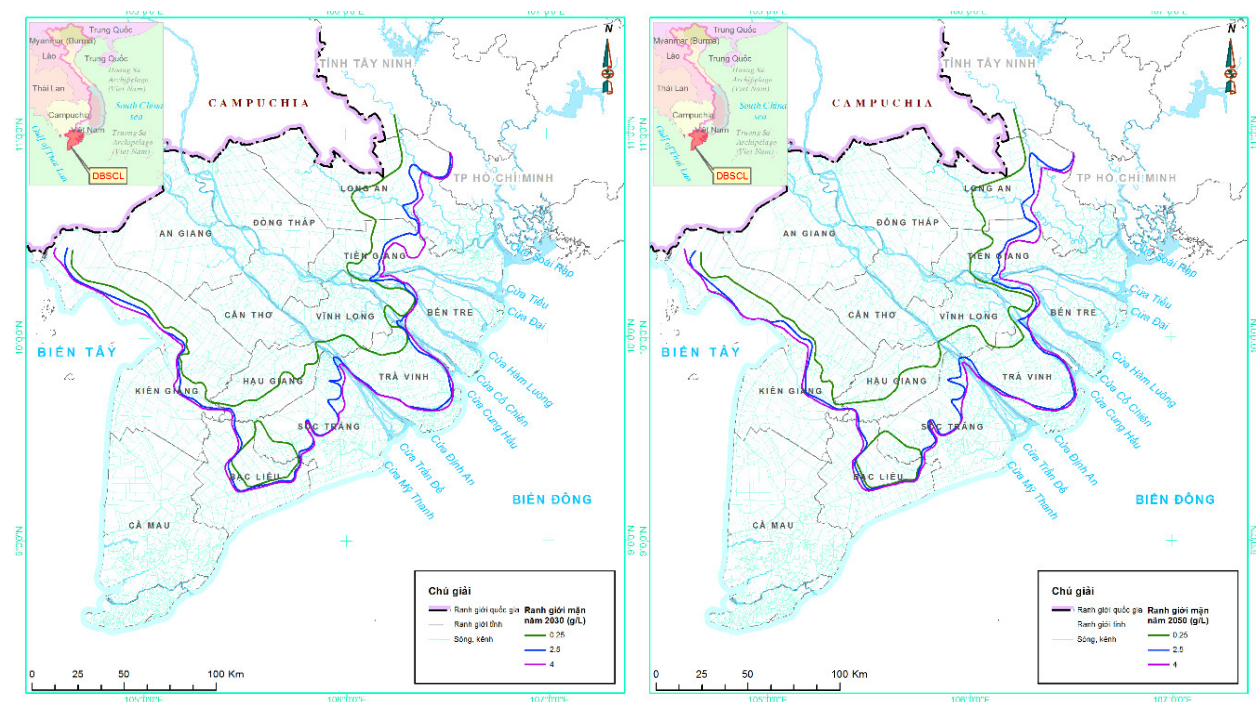

Hình 3. Bản đồ phân bố xâm nhập mặn lớn nhất trong sông năm 2015 và 2016
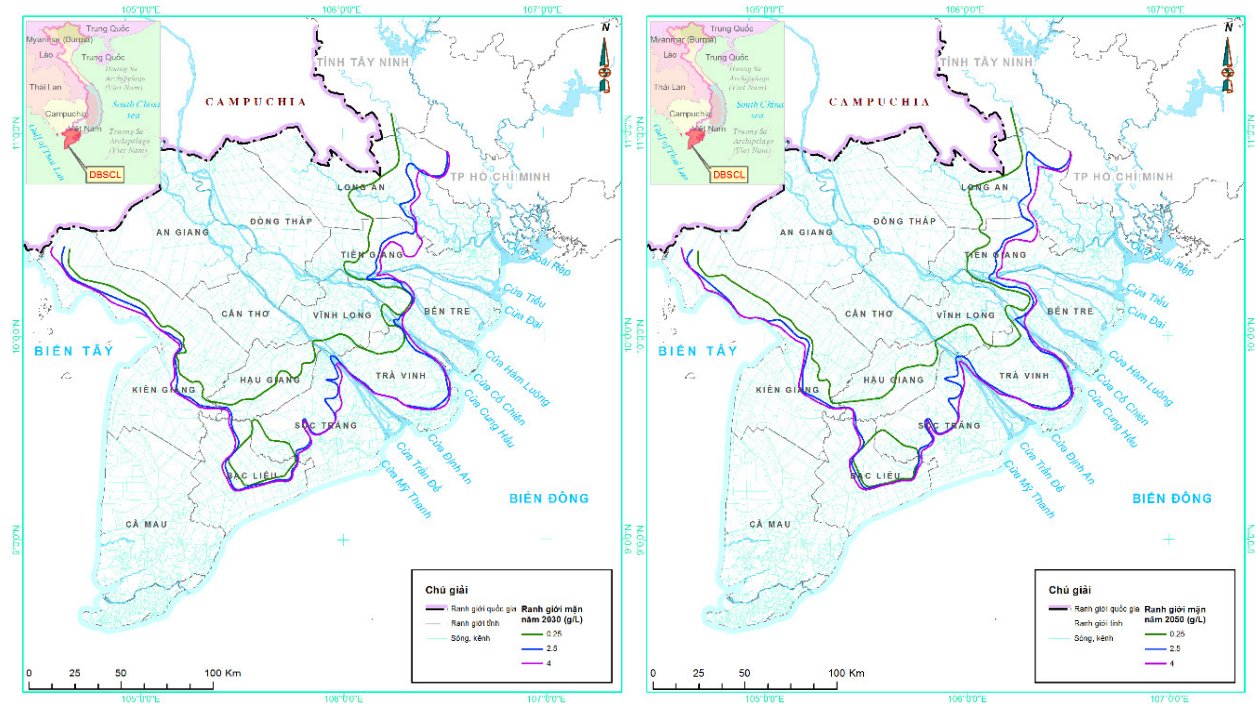

Hình 4. Bản đồ phân bố xâm nhập mặn lớn nhất trong sông năm 2030 và 2050

Đối với hiện trạng xâm nhập mặn năm 2016, các ranh giới mặn đều cao hơn so với kịch bản nền năm 2015, kết quả này phản ánh đúng tình hình thực tế và đã chứng minh tính phù hợp của mô hình mô phỏng.

Đối với kịch bản 3 và 4 , tác động của $\mathrm{BĐKH-}$ NBD xâm nhập mặn được dự đoán lấn sâu nhất vào đất liền thuộc khu vực 2 sông Vàm Cỏ, sông Tiền và sông Hậu, tức là các của sông phía biển Đông. Ngược lại, dự báo xâm nhập mặn năm 2030 và 2050 có xu hướng giảm phía bắc ven biển Tây, nguyên nhân là do khi nước biển dâng thì triều biển Đông chiếm ưu thế hơn đồng thời chế độ thủy lực thay đổi theo hướng lượng nước về phía Tứ giác Long Xuyên.

Riêng đối với của sông Cái Lớn và Cái Bé có sự tranh chấp giữa triều biển Đông và triều biển Tây, nên xâm nhập mặn ở đây rất phức tạp, cụ thể khi có tác động của nước biển dâng ở mức độ vừa phải (kịch bản 3 với triều dự báo cao hơn hiện trạng $12 \mathrm{~cm}$ ) xu thế mặn giảm, nhưng nếu tác động lớn (kịch bản 4 với triều cao hơn hiện trạng $22 \mathrm{~cm}$ ), lượng nước thượng nguồn về sẽ bị ép lên ngược lên cao hơn, do đó xu thế mặn lại tăng lên.

3.3. Cân bằng nước và xác định khan hiếm nguồn nước mùa khô

Cân bằng nước được tính toán giữa nguồn 
nước có thể đáp ứng và nhu cầu nước cho 120 khu thủy lợi thuộc 22 tiểu vùng trên toàn ĐBSCL. Bởi vì nhu cầu nước cho nông nghiệp chiếm tỷ trọng lớn (trên 90\%), nguồn nước có thể đáp ứng cho nhu cầu được xét trên cơ sở ngưỡng mặn 2,5 g/l. Dựa trên kết quả mô phỏng thủy động lực xâm nhập mặn mùa khô từ tháng 1 đến tháng 6 , kết quả tính toán lượng nước thiếu hụt ở 22 tiểu vùng ở ĐBSCL được thể hiện trong Bảng 4.

Bảng 4 cho thấy trong mùa khô năm 2015 lượng nước thiếu hụt là 4.065 triệu $\mathrm{m}^{3}$ và năm
2016 là 4.201 triệu $\mathrm{m}^{3}$. Lượng thiếu hụt năm 2016 tăng so với 2015 bởi mùa khô năm 2016 triều cao và dòng chảy thượng nguồn về ĐBSCL thấp so với năm 2015, làm cho xâm nhập mặn tiến sâu hơn vào nội đồng. Mặc dù lượng thiếu hụt tăng chỉ khoảng 136 triệu m³ m $^{3} 016$ được coi là năm hạn và gây thiệt hại lớn nhất về nông sản ĐBSCL trong thời gian qua. Điều này được lý giải là do năm 2016 xâm nhập mặn lớn xuất hiện sớm vào tháng 2 (thời điểm chưa thu hoạch vụ Đông-Xuân), trong khi quy luật thường rơi vào tháng 3 hoặc tháng 4 hàng năm.

Bảng 4. Nhu cầu (NC) và sụ thiếu hụt nguồn nước (TH) vào mùa khô ở 22 tiểu vùng ĐBSCL

\begin{tabular}{ccccccccc}
\hline \multirow{2}{*}{ Tiểu } & \multicolumn{7}{c}{ Kịch bản $\left(\right.$ Triệu $\left.\mathrm{m}^{3}\right)$} \\
\cline { 2 - 8 } vùng & \multicolumn{2}{c}{2015} & \multicolumn{2}{c}{2016} & \multicolumn{2}{c}{2050} \\
\cline { 2 - 8 } & NC & TH & NC & TH & NC & TH & NC & TH \\
\hline I & 567,6 & 0,2 & 567,6 & 30,0 & 472,3 & 0,6 & 490,2 & 5,3 \\
II & 202,5 & 0 & 202,5 & 0 & 169,6 & 0 & 171,8 & 0 \\
III & 1210 & 0 & 1210 & 0 & 1.350 & 0 & 1.385 & 0 \\
IV & 2.033 & 0 & 2.033 & 0 & 2.625 & 0 & 2.643 & 0 \\
V & 744,2 & 471,7 & 744,2 & 472,3 & 877,9 & 539,9 & 872,3 & 547,1 \\
VI & 1.346 & 1.019 & 1.346 & 1.031 & 1.729 & 1341 & 1.741 & 1.350 \\
VII & 337,4 & 337,4 & 337,4 & 337,4 & 347,0 & 347,0 & 349,7 & 349,7 \\
VIII & 625,8 & 605,1 & 625,8 & 605,1 & 709,7 & 688,5 & 722,2 & 700,4 \\
IX & 151,6 & 151,6 & 151,6 & 151,6 & 132,4 & 132,3 & 140,3 & 140,3 \\
X & 466,5 & 466,5 & 466,5 & 466,5 & 443,2 & 443,2 & 451,1 & 451,1 \\
XI & 185,6 & 0 & 185,6 & 0 & 204,8 & 0 & 211,5 & 0 \\
XII & 452,1 & 0 & 452,1 & 0 & 515,7 & 0 & 531,2 & 0 \\
XIII & 894,2 & 0 & 894,2 & 0 & 1.354 & 0 & 1.354 & 0 \\
XIV & 1.129 & 223,6 & 1.129 & 285,1 & 1.562 & 326,1 & 1.585 & 337,8 \\
XV & 353,8 & 139,0 & 353,8 & 172,4 & 363,9 & 146,7 & 415,5 & 169,5 \\
XVI & 487,0 & 35,2 & 487,0 & 31,1 & 440,8 & 51,5 & 492,5 & 76,2 \\
XVII & 360,7 & 360,7 & 360,7 & 360,7 & 381,7 & 381,8 & 408,1 & 408,1 \\
XVIII & 1.057 & 0 & 1.057 & 0 & 1.149 & 4,4 & 1.202 & 5,0 \\
XIX & 1.715 & 0 & 1.715 & 0 & 1.858 & 0 & 1.867 & 0 \\
XX & 234,2 & 0 & 234,2 & 0 & 252,9 & 0 & 253,4 & 0 \\
XXI & 597,9 & 119,7 & 597,9 & 122,1 & 688,8 & 298,9 & 680,8 & 297,8 \\
XXII & 307,1 & 135,5 & 307,1 & 135,5 & 322,0 & 190,9 & 328,2 & 214,6 \\
Tồng & 15.458 & 4.065 & 15.458 & 4.201 & 17.950 & 4.893 & 18.295 & 5.053 \\
\hline
\end{tabular}

Trong tương lai, lượng thiếu hụt vào mùa khô dự báo tăng xấp xỉ 4 - 5\%, tương ứng 4.893 triệu $\mathrm{m}^{3}$ (năm 2030) và 5.053 triệu $\mathrm{m}^{3}$ (năm 2050) do nhu cầu sử dụng nước cả năm tăng $20 \%$ (28,6 tỷ $\mathrm{m}^{3}$ năm 2030) đến $22 \%$ (29,2 tỷ $\mathrm{m}^{3}$ năm 2050) và xâm nhập mặn tiến sâu hơn vào nội đồng như đã phân tích ở trên.

\section{Kết luận}

Thông qua tính toán $\mathrm{NCN}$ và mô phỏng chế độ thủy văn, thủy lực, xâm nhập mặn của vùng ĐBSCL bằng mô hình MIKE 11, nghiên cứu đã mô tả được "bức tranh" tổng thể về sự thiếu hụt 


\section{BÀI BÁO KHOA HỌC}

nguồn nước ngọt hàng tháng ở 120 khu thủy lợi thuộc 22 tiểu vùng của ĐBSCL trong giai đoạn hiện trạng, đến năm 2030 và 2050 dưới tác động tổng hợp của các yếu tố như gia tăng $\mathrm{NCN}$, BĐKH-NBD.

Phân tích tác động tổ hợp của sự gia tăng nhu cầu nước và diễn biến xâm nhập mặn đã cho thấy hiện trạng thiếu hụt nguồn nước vào các tháng mùa khô ở ĐBSCL đã rất lớn, khoảng 4,0 tỉ $\mathrm{m}^{3}$. Dự báo lượng thiếu hụt trong mùa khô sẽ là 4,8 tỉ m³ vào năm 2030 và 5,1 tỉ m³ vào năm 2050 . Điều này là do nhu cầu sử dụng nước trong tương lai tăng 20\% năm 2030 đến 22\% năm 2050 so với hiện trạng 22,8 tỉ m³ , đặc biệt $\mathrm{NCN}$ trong các tháng mùa khô NCN tăng 41,3\% $42,7 \%$ và xâm nhập mặn lấn sâu hơn vào nội đồng so với hiện trạng.

Với kết quả tính toán trên cơ sở dữ liệu và phương pháp nghiên cứu phù hợp, đảm bảo độ tin cậy, nghiên cứu không chỉ đáp ứng về mặt khoa học, mà còn có ý nghĩa thực tiễn, góp phần cung cấp thông tin có giá trị cho quản lý, quy hoạch, khai thác sử dụng tài nguyên đất và nước ở ĐBSCL.

Lời cảm ơn: Bài báo này là kết quả tù đề tài "Nghiên cưu giải pháp quy hoạch vùng Đồng Tháp Mười trở thành vùng trũ nước ngọt cho khu vực đồng bằng sông Cưu Long thích úng với biến đổi khi hậ" được tài trọ̣ bởi Chuơng trình Khoa học và Công nghệ úng phó với biến đổi khí hậu, quản lý tài nguyên và môi truòng giai đoạn 2016-2020, mã số đề tài BĐKH.11/16-20, thông qua Hơp đồng số 11/HĐ-KHCN-BĐKH/16-20, ngày 29/12/2016. Các tác giả cũng bày tỏ lòng cảm ơn chân thành tới Tạp chí, nhũng người phản biện để bài báo được hoàn thành.

\section{Tài liệu tham khảo}

1. Cấn Thu Văn, Nguyễn Thanh Sơn (2016), Nghiên cưu mô phỏng thủy văn, thủy lực vùng đồng bằng sông Cưu Long để đánh giá ảnh hưởng của hệ thống đê bao đến sụ thay đổi dòng chảy mặt vùng Đồng Tháp Mười. Tạp chí Khoa học ĐHQGHN: Các Khoa học Trái đất và Môi trường, 32 (3S), 256-263.

2. Chu,T.H., Facon, T., Try Thuon, Bastakoti, R.C., Molle, F., Phengphaengs, F., (2009), Irrigation in the Lower Mekong Basin Countries: The Beginning of a New Era?. Contested Waterscapes in the Mekong Region Earthscan, 144-171.

3. Dang, K.N., Nguyen,V.B., Nguyen, H.T., (2007), Chapter 4: Water Use and Competition in the Mekong Delta, Vietnam.

4. Đặng Đình Khá, Trần Ngọc Anh, Mai Thị Nga (2015), Cân bằng nước lưu vục sông Lam bằng mô hình WEAP. Tạp chí Khoa học: Khoa học Tự nhiên và Công nghệ, 31 (3S), 186-194.

5. Đoàn Quang Trí (2016), Úng dụng mô hình MIKE 11 mô phỏng và tính toán xâm nhập mặn cho khu vực Nam Bộ. Tạp chí Khí tượng Thủy văn, 671, 39-46.

6. FAO (2011), Irrigation in Southern and Eastern Asia in figures - AQUASTAT Survey, Mekong Rive Basin.

7. JICA (2003), Chương 6: Dư báo nhu cầu nước trong 14 lưu vục sông. Nghiên Cứu Phát Triển Và Quản Lý Tài Nguyên Nước Trên Toàn Quốc.

8. Mekong River Commission (2005), Water Used for Agriculture in the Lower Mekong Basin.

9. Nguyễn Xuân Phùng (2007), Úng dụng mô hình MIKE 11 trong tính toán thuỷ văn, thuỷ lục mùa lũ lưu vục sông Ba. Tạp chí Khoa học kỹ thuật Thủy lợi và Môi trường, 16, 1-10.

10. Van, P.D.T., Popescu, I., van Griensven, A., Solomatine, D.P., Trung, N.H. Green, A., (2012), A study of the climate change impacts on fuvial flood propagation in the Vietnamese Mekong Delta. Hydrol. Earth Syst. Sci. 16, 4637-4649.Doi:10.5194/hess-16-4637-2012.

11. Tô Quang Toản, Tăng Đức Thắng (2016), Phân tích ảnh huoơng của các hồ đập thượng luu 
đến thay đổi thủy văn dòng chảy mùa khô về châu thổ Mê Công. Tạp chí Khoa học và Công nghệ thủy lợi, 31,1-7.

12. Sagris, T., Tahir, S., Jennifer, M.G., Nguyen,V.Q., Abbott, J., Yang, L., (2017), Viet Nam: Hydro-Economic Framework for Assessing Water Sector Challenges, 2030 Water Resources Group.

13. Trần Quốc Đạt, Nguyễn Hiếu Trung, Kanchit Likitdecharote (2012), Mô phỏng xâm nhập mặn đồng bằng sông cửu long dưới tác động mực nước biển dâng và sụ suy giảm lưu lượng tù thương nguồn. Tạp chí Khoa học, 2012:21b, 141-150.

\title{
FRESH WATER DEFICIT IN THE LOWER MEKONG DELTA: CUR- RENT DEVELOPMENT AND FORECAST FOR 2030 AND 2050 UNDER THE IMPACTS OF CLIMATE CHANGE Tran Xuan Hai', Bui Nguyen Lam Ha², Pham Anh Tai', Do Ngoc Tuan', Vu Van Nghi ${ }^{3}$, Dang Thanh Lam ${ }^{4}$ \\ ${ }^{1}$ Institute for Science and Technology Innovation, HCMC \\ ${ }^{2}$ Da Lat University, Da Lat City, Lam Dong province \\ ${ }^{3}$ University of Science, Viet Nam National University Ho Chi Minh City \\ ${ }^{4}$ Southern Institute for Water Resources Planning, Ho Chi Minh City
}

\begin{abstract}
Current development and forecast of scarcity of fresh water sources for 120 sub-areas in the Lower Mekong Delta under socio-economic development and climate change-sea level rise scenarios are evaluated based on the water balance calculation through steps such as water demand estimation and salinity intrusion simulation using MIKE11 model. The results show that the fresh water shortage in the dry season in the Lower Mekong Delta is currently about 4.0 billion $\mathrm{m}^{3}$, forecast to reach 4.8 billion $m^{3}$ in 2030 and 5.0 billion $m^{3}$ in 2050. The reason is that the annual demand for fresh water in the Mekong Delta is significant with the present value of about 22.8 billion $m^{3}$, increasing to 28.6 billion $m^{3}$ in 2030 and 29.2 billion $m^{3}$ in 2050; along with that, saline intrusion is increasingly entering the field.
\end{abstract}

Keywords: Fresh water deficit, Lower Mekong Delta, salinity intrusion, water balance. 